\title{
Changes in plasma progesterone and prolactin concentrations during the annual cycle and the role of prolactin in the maintenance of lactation and luteal development in the Antarctic fur seal (Arctocephalus gazella)
}

\author{
I. L. Boyd \\ British Antarctic Survey, Natural Environment Research Council, High Cross, Madingley Road, \\ Cambridge CB3 OET, UK
}

\begin{abstract}
Summary. Progesterone in Antarctic fur seals was undectable from 1-2 days before parturition to 4-6 days after parturition. There was a rapid increase in progesterone to $20 \mathrm{ng} / \mathrm{ml}$ between 6 and 10 days post partum and this increase coincided with peak concentrations of oestradiol-17 $\beta$ at the time normally associated with oestrus and mating in this species. Newly formed corpora lutea were present in the ovaries by Day 9 post partum even though the seals had been isolated in an enclosure and not mated. Thereafter, progesterone remained detectable, but at a low concentration $(5 \mathrm{ng} / \mathrm{ml})$ throughout embryonic diapause. A similar pattern was observed in unmated females which suggests they enter a period of pseudopregnancy. Progesterone increased to $35 \mathrm{ng} / \mathrm{ml}$ between late February and mid-March, indicating activation of the corpus luteum at the end of diapause, and then declined slowly through the remainder of gestation. Plasma prolactin, measured against a human prolactin standard, was elevated from 1-2 days before parturition and peaked at $0-3$ days post partum. It then declined slowly throughout the post-partum period and remained at a low level throughout embryonic diapause. Prolactin concentration declined to undetectable at the end of diapause and before the end of lactation. Reduction of prolactin secretion by injections of bromocriptine from Days 3 to 5 post-partum terminated lactation. Mothers, which normally leave their pups to feed at sea on about Day 7 post partum, did not continue to lactate beyond Day 7 although this did not appear to be associated with reduced prolactin secretion. Bromocriptine treatment appeared to prevent the postovulatory surge of progesterone although there was no long-term effect of bromocriptine on progesterone secretion during the early stages of embryonic diapause/ pseudopregnancy. This study has shown that prolactin is an important hormone for maintaining early lactation in the fur seal and it probably also has a role in the control of ovulation and luteal development. Prolactin does not appear to be implicated in the control of lactation cycles in fur seals. Changes in plasma progesterone during the annual cycle show that the pattern in fur seals resembles that of some carnivores with embryonic diapause.
\end{abstract}

Keywords: Antarctic fur seal; progesterone; prolactin; post-partum oestrus; lactation

\section{Introduction}

Reproduction in pinnipeds is characterized by synchronous annual cycles and a period of embryonic diapause lasting 3-4 months (Daniel, 1981; Boyd, in press). Amongst the otariids (sea 
lions and fur seals), mating occurs 6-10 days post partum. In the Antarctic fur seal (Arctocephalus gazella) lactation lasts about 4 months (December to April) and during this time females alternate between foraging at sea for 3-6 days and being ashore to feed their pups for 1-2 days (Doidge \& Croxall, 1989). The mean time between arrival at the colony and birth is $43 \mathrm{~h}$ (Doidge et al., 1986) and mothers begin to suckle within a few hours of parturition. The number of secondary follicles in the ovaries begins to increase at parturition (Laws, 1956; Craig, 1964; Boyd, 1983), suggesting an increased rate of folliculogenesis at this time and this leads to ovulation several days later. Previous studies of pinnipeds have shown that progesterone secretion declines in advance of parturition and is undetectable until ovulation when secretion resumes from the new corpus luteum (Raeside \& Ronald, 1981; Boyd, 1983; Reijnders, 1990).

Prolactin has a central role in the development of the mammary gland and the maintenance of lactation in many mammals, although this is often associated with an effect of regular suckling on prolactin secretion (e.g. McNeilly et al., 1982; Loudon et al., 1983; Schirar et al., 1990). In the fur seal, it seems less likely that nipple stimulation is responsible for the maintenance of lactation because mothers are regularly separated from the pup while feeding at sea for periods of several days (Doidge et al., 1986; Doidge \& Croxall, 1989). Prolactin is also implicated as a luteotrophic hormone in several carnivores (Murphy, 1979; Agu et al., 1986; Concannon et al., 1987) and it may be partly responsible for luteal reactivation at the end of embryonic diapause (Martinet et al., 1981; Murphy et al., 1981). Therefore, prolactin is likely to have a significant role in the physiological control of the post-partum oestrous cycle, embryonic diapause and lactation in pinnipeds.

Antarctic fur seals are a major predator in the ecosystem of the Southern Ocean (Croxall et al., 1988). Lactation is the stage of the reproductive cycle when there is greatest energetic stress on females (Boyd \& McCann, 1989; Doidge \& Croxall, 1989; Costa et al., 1989) and the success of lactation may be used as a measure of the resources available to the population (Croxall et al., 1988). It is important to understand the link between the behaviour of lactating females, particularly in relation to the duration and characteristics of their foraging-suckling cycles, and the endocrine control of reproduction. This study examined some endocrine changes occurring during the lactation cycles of these seals and, in particular, the role of prolactin in the control of lactation. This involved (a) treating lactating females with the dopamine agonist bromocriptine to reduce circulating prolactin concentrations and (b) extending the period of time spent ashore by mothers to examine the hormonal changes which normally occur when females leave their pup and depart to feed at sea. Additional aims were to describe the annual cycle of plasma progesterone and prolactin concentrations and the hormonal changes occurring between parturition and oestrus.

\section{Materials and Methods}

Study animals and measurements. Adult female Antarctic fur seals, which were part of the large breeding population $(\sim 50000)$ at Bird Island, South Georgia $\left(54^{\circ} \mathrm{S}, 38^{\circ} \mathrm{W}\right)$, were used in this study. Individuals were captured with a noose pole and restrained by the method of Gentry \& Holt (1982). Females used in the experiments involving measurements between parturition and oestrus were captured within $24 \mathrm{~h}$ of arriving at the breeding colony and before they had given birth. These seals were placed in a $6 \mathrm{~m} \times 4 \mathrm{~m}$ enclosure which was within $30 \mathrm{~m}$ of one of the main breeding beaches. No more than 8 seals were in the enclosure simultaneously and this meant that the seals were kept at a density similar to that which may be found on the breeding beaches. The purpose of enclosing females was both to exclude males and to allow females to be sampled at regular intervals without the stress of capture.

Blood (usually 3-5 ml) was sampled from a rear flipper into heparinised syringes (Sarstedt Ltd, Leicester LE4 $1 \mathrm{AW}, \mathrm{UK}$ ) which were then centrifuged within $1 \mathrm{~h}$ of collection at $2000 \mathrm{~g}$ for $10 \mathrm{~min}$. Plasma was stored at $-20^{\circ} \mathrm{C}$ and returned to the UK by ship.

Seals were weighed while in a restraint board (Gentry \& Holt, 1982), using a $100 \mathrm{~kg}$ spring balance (accuracy $0.25 \mathrm{~kg},<1 \%$ of mean post-partum mass) suspended from a tripod. Pups were weighed by placing them in a light nylon bag and suspending them from a $10 \mathrm{~kg}$ spring balance (accuracy of the balance $0.05 \mathrm{~kg},<1 \%$ of birth mass).

Experiment 1. Blood samples $(n=103)$ were obtained from adult female Antarctic fur seals at different times of the year. Females are normally only ashore at the breeding grounds during the pup rearing period (December-April) (Boyd, 1989) and at other times they are feeding at sea. Therefore, most samples were obtained from seals captured 
during the pup rearing period, when many of the seals sampled were seen with their pups. Females are rarely seen ashore during the winter (April-October) and were therefore unavailable for sampling at this time. However, a special effort was made to sample females coming ashore for short periods during August and September (late gestation). Females were released after capture but it was not practical to sample the same female more than once. Sampling was carried out in bouts so that several females were sampled within a period of 5-7 days and the results of hormone determinations of the plasma of these groups were combined as a mean and plotted with time of year.

Experiment 2. Seven pregnant seals were kept in the enclosure from immediately before birth until 7 days after birth, the normal duration of the post-partum attendance period. Blood was sampled between 08:00 and 09:00 h daily. Although females had visual contact with males in the vicinity of the enclosure, they were prevented from being mated by being kept apart from males. At the end of the experiment females were killed under licence (issued to investigate aspects of reproduction and concentrations of chemical pollutant in tissues). The ovaries were removed and examined for the presence of corpora lutea and corpora albicantia.

Experiment 3. Eighteen pregnant females were captured and placed in the enclosure within $24 \mathrm{~h}$ of their arrival at the pupping grounds. These seals were allocated at random to three groups $(\mathrm{N}=6$ for each group). Group D7 was kept in the enclosure for 7 days after birth; Group D10 was kept in the enclosure for 10 days after birth and Group brD10 was given a daily injection (i.m.) of $0.2-0.4 \mathrm{mg}$ bromocriptine/ $\mathrm{kg}$ (2-bromo- $\alpha$-ergocryptine methanesulphonate: Sigma Chemical Company, Poole, Dorset BH17 7NH, UK) from Days 2 to 4 post partum (i.e. 3 consecutive days) and kept in the enclosure for 10 days. Bromocriptine was made up as a suspension in $0.85 \%(\mathrm{w} / \mathrm{v})$ saline. Vehicle, with bromocriptine added was given to seals in Group D10 at the same times relative to parturition as injections were given to Group brDl0 seals. Before the start of bromocriptine treatment, all seals in each group were checked to ensure that they were lactating. This was done by injecting (i.m.) $1 \mathrm{ml}$ of oxytocin solution (Oxytocin F, $10 \mathrm{IU} / \mathrm{ml}$, Veterinary Drug Company, Bury St Edmunds, Suffolk IP33 3TU, UK) then milking using a 50-ml syringe with the end cut off. This was used to create the suction necessary to cause nipple eversion and milk ejection.

At the end of the period in the enclosure, seals were released to go to sea and feed. Seals were then recaptured on their return to suckle their pups and reunited with their pup in the enclosure for 2 days. At the end of this period both mothers and pups were released.

Blood was sampled from mothers at first capture, on the day of parturition, 7 days after parturition and, for seals in Groups D10 and brD10, 10 days after parturition. Additional samples were also obtained from Groups D10 and brD10 5 days after parturition. Mothers and pups were also weighed at the same times as blood samples were obtained.

Hormone assays. Oestradiol-17 $\beta$, progesterone and prolactin were assayed using an enzyme immunoassay developed for the measurement of these hormones in human plasma ('Serozyme', Serono Diagnostics Ltd, Woking, Surrey GU21 5JY, UK). In this study, the assays were modified to use small volumes of plasma by reducing the total volume of the assays by one quarter and running them on micro-titre plates. All reagents were used at the concentrations at which they were supplied. In the case of the steroid assays, plasma $(50 \mu \mathrm{l}$ for oestradiol and $12.5 \mu \mathrm{l}$ for progesterone) was incubated at $37^{\circ} \mathrm{C}$ for $20 \mathrm{~min}$ with fluorescein-labelled monoclonal antibody and a standard quantity of enzyme labelled steroid. In the prolactin assay, plasma $(25 \mu \mathrm{l})$ was incubated at $37^{\circ} \mathrm{C}$ for 20 min with two monoclonal antibodies specific to different parts of the prolactin molecule. One was labelled with fluorescein and the other with enzyme. Anti-fluorescein coupled to a magnetic solid phase was then added in excess and incubated at $37^{\circ} \mathrm{C}$ for $10 \mathrm{~min}$. After magnetic separation, the supernatant was discarded and the sediment was washed with sodium phosphate buffer. Separation was repeated and the sediment was incubated for $30 \mathrm{~min}$ at $37^{\circ} \mathrm{C}$ with a standard volume of enzyme substrate before the reaction was stopped with a weak solution of sodium hydroxide as provided by the suppliers of the assay. The blank-corrected absorbance of the supernatant was then read at $550 \mathrm{~nm}$ on a Cambridge Life Sciences CLS962 Microplate Photometer and hormone concentrations were determined from a standard curve run in duplicate with each plate. Samples of seal plasma were assayed in duplicate. The prolactin standard was human prolactin with biological activity calibrated against the 2nd IRP for hPRL (83/562).

Pooled plasma from male fur seals was used as the blank in both the steroid assays and assay diluent was used in the prolactin assay. These gave values below the limits of detection which were the concentrations equivalent to the absorbance of the blank minus (or plus in the case of the prolactin assay) two standard deviations $(20 \mathrm{pg} / \mathrm{ml}$ for oestradiol, $0.2 \mathrm{ng} / \mathrm{ml}$ for progesterone and $0.5 \mathrm{ng} / \mathrm{ml}$ for prolactin). Addition of a known mass of steroid gave mean recoveries of $80.35 \pm 3.1 \%$ for oestradiol and $112.5 \pm 12.5 \%$ for progesterone. A plasma sample which gave a high $(40 \mathrm{ng} / \mathrm{ml})$ value for prolactin in the assay was diluted in assay diluent at $1: 1.5$ to 1.25 and this gave a dilution curve parallel to the standard curve. The slope of the regression between observed and expected values was 1.3 and the regression coefficient $\left(r^{2}\right)$ was 0.954 . The top prolactin standard $(250 \mathrm{ng} / \mathrm{ml}$ or $5000 \mu$ i.u. $/ \mathrm{ml})$ diluted in seal plasma also gave a dilution curve parallel to the standard curve, suggesting that plasma effects did not invalidate the assay. In the circumstances, it was not possible to validate the assay using dilution of pituitary extracts, although this procedure will be carried out in due course. The intra-assay coefficient of variation was $8.4 \%, 6 \cdot 1 \%$ and $9 \cdot 1 \%$ for oestradiol, progesterone and prolactin respectively and the inter-assay coefficient of variation was $9.4 \%, 6.4 \%$ and $15.8 \%$ for oestradiol, progesterone and prolactin respectively. These coefficients of variation were calculated for quality controls of $170 \mathrm{pg} / \mathrm{ml}, 5.4 \mathrm{ng} / \mathrm{ml}$ and $6.5 \mathrm{ng} / \mathrm{ml}$ for oestradiol, progesterone and prolactin respectively. The values of quality control samples supplied with the assay kits were within the range quoted by the supplier. Cross-reactions in the oestradiol assay were only significant for oestradiol sulphate $(5 \cdot 2 \%)$ and oestradiol $3 \beta$-D-glucuronide $(81 \cdot 1 \%)$. In the progesterone assay there was $100 \%$ cross-reaction with 11 -hydroxyprogesterone and other significant cross- 
reactions were with pregnenolone-3-glucuronide (8.0\%) and 5a-pregnanedione (14.5\%). There was no significant cross-reaction with either $17 \alpha$-hydroxyprogesterone or $20 \alpha$-dihydroprogesterone. In the prolactin assay, there were no cross-reactions with hLH, hFSH or hTSH but there was $7 \%$ cross-reaction with hGH.

Statistical analysis. Student's $t$ test was used to estimate the probability of mean values of controls being different from treated seals with a limit of significance of 0.05 .

\section{Results}

\section{Experiment 1: the annual cycle of progesterone and prolactin}

The concentration of plasma progesterone was between 2 and $10 \mathrm{ng} / \mathrm{ml}$ for the period between December and February which corresponds to the first half of lactation (Fig. 1). Between late February and mid-March the concentration increased to $10-30 \mathrm{ng} / \mathrm{ml}$ by the final stages of lactation and remained at $15 \mathrm{ng} / \mathrm{ml}$ until August (Fig. 1). Thereafter, the concentration of progesterone declined to $<1 \mathrm{ng} / \mathrm{ml}$ during the final few days of gestation (Fig. 1). Prolactin concentrations were between 1 and $10 \mathrm{ng} / \mathrm{ml}$ from birth until early February but then declined to undetectable concentrations from April until September. Prolactin then increased to $5-10 \mathrm{ng} / \mathrm{ml}$ at the end of gestation although sampling was not frequent enough to be able to say when the increase occurred between late September and early December. Prolactin declined to undetectable concentrations simultaneously with a rapid increase in the concentration of progesterone in the plasma. Both the increase in progesterone and the decline in prolactin occurred before the end of lactation in early April (Fig. 1). Overall, there was a significant negative correlation between progesterone and prolactin concentrations $(r=-0.441, P<0.001)$.

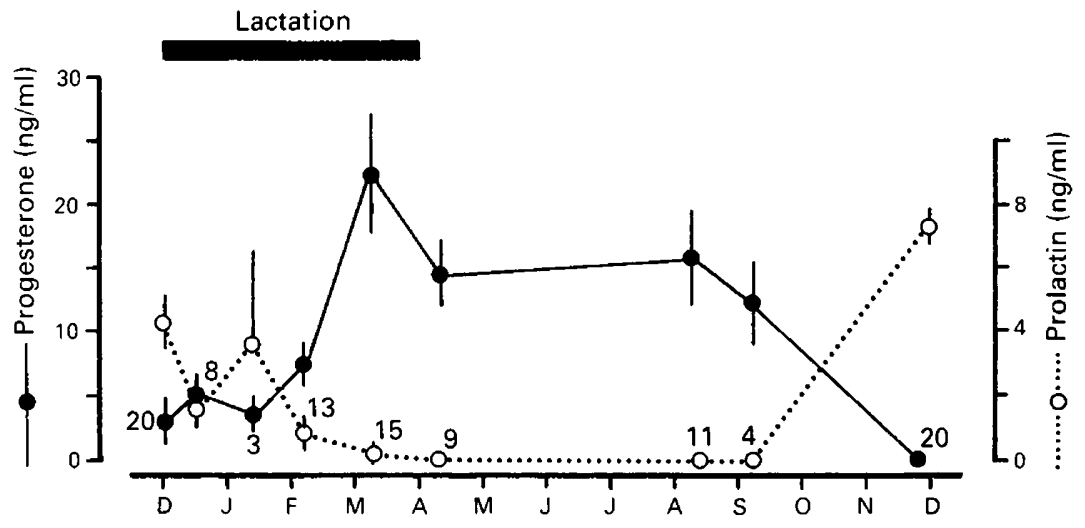

Fig. 1. Changes in plasma progesterone and prolactin concentrations during the annual cycle. Each point is a mean ( \pm s.e.) of samples taken over 5-7-day periods and sample sizes are shown.

\section{Experiment 2: the post-partum oestrous cycle}

Plasma progesterone concentration was below the sensitivity of the assay for the first 4-6 days after parturition. Between 4 and 6 days post partum, the plasma progesterone concentration increased sharply although the magnitude of the increase was quite variable (peak at 3-38 ng/ml) (Fig. 2). The increase in plasma progesterone was usually accompanied by increased concentrations of plasma oestradiol. The concentration of oestradiol showed a clear double peak $(60-110 \mathrm{pg} / \mathrm{ml})$ in 5 of the 7 seals; an early peak at 1-3 days post partum and a later peak $(90-150 \mathrm{pg} / \mathrm{ml})$ at $5-6$ days post partum (Fig. 2). It is possible that in the other 2 seals, in which only an early peak was 
observed in one (Seal G, Day 3 post partum) and only a late peak in the other (Seal F, Day 6 post partum), the other peak could have been missed due to the relatively infrequent sampling.

In 5 of the seals plasma prolactin showed a peak concentration $(1.5-9.5 \mathrm{ng} / \mathrm{ml})$ at $1-3$ days after parturition and the prolactin concentration was generally highest during the early stages of the post-partum period.

Ovulation had occurred in all seals by 9 days after parturition. This was indicated by the presence of an ovulation stigma on the surface of one ovary from each seal and an associated corpus luteum. The contralateral ovary in every female contained a large corpus albicans.

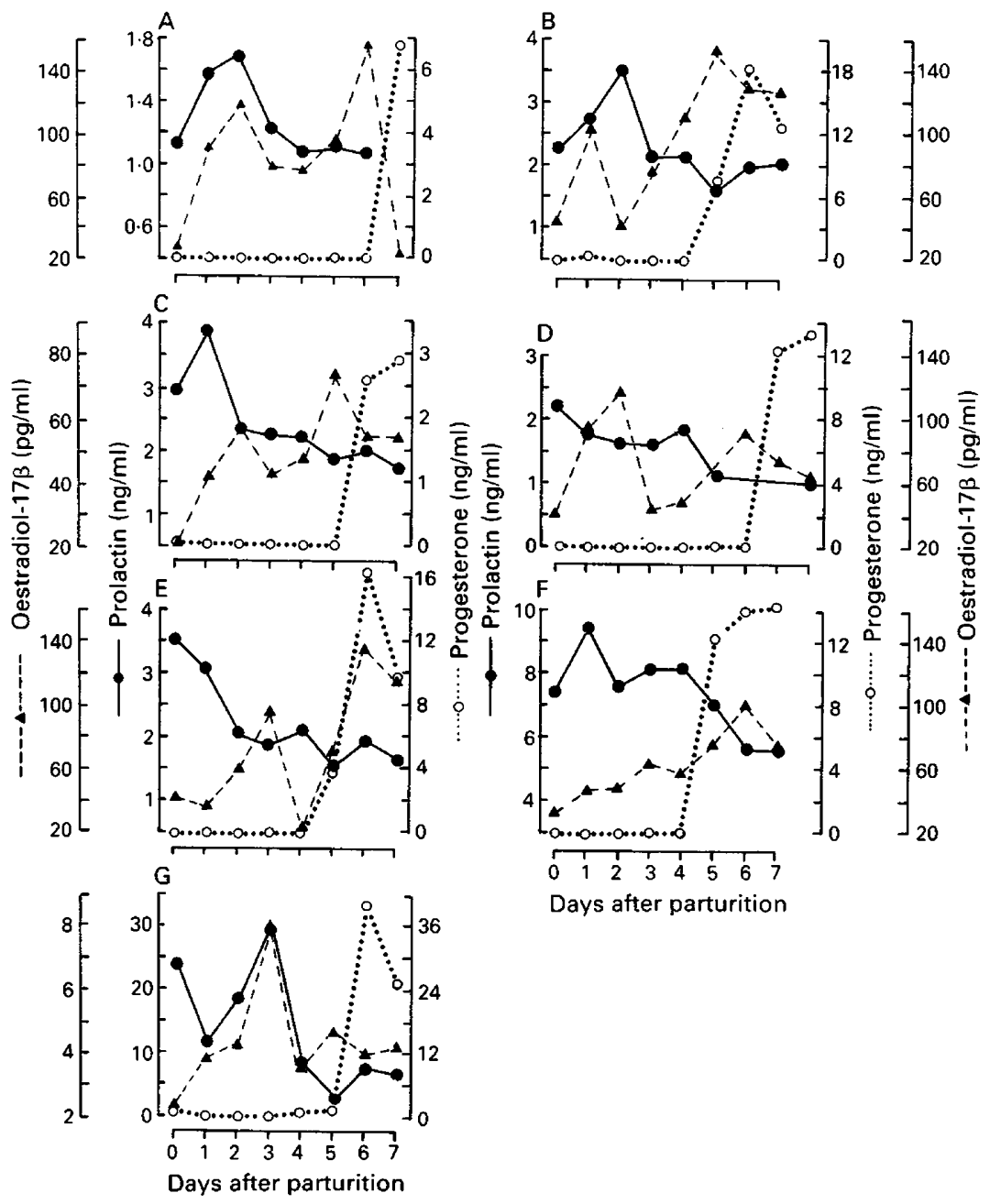

Fig. 2. Patterns of plasma oestradiol-17 $\beta$, progesterone and prolactin in 7 female Antarctic fur seals (Arctocephalus gazella) from parturition until after the normal time of post-partum oestrus.

\section{Experiment 3: effect of bromocriptine treatment on early lactation}

All seals were lactating, as judged by the presence of milk, during Days 1-3 post partum. There was no significant difference between the plasma prolactin concentrations of the three groups on 
the day of birth ( $P>0.1$ in each comparison) although the concentration in the plasma of Group D7 animals was significantly lower than in the other two groups at the time of capture $(t=2 \cdot 60$, $P<0.05$ ) (Fig. 3). At both 7 and 10 days after parturition, the concentration of prolactin in Group brD10 was significantly lower than the concentration in Group D10 (Day $7, t=2.54, P<0.05$; Day $9, t=3.77, P<0.001$ ). However, the plasma prolactin concentration in each of these groups was not significantly different from Group D7 in samples taken 7 days after parturition $(P>0.05$, Fig. 3). The plasma prolactin concentration was also significantly lower in Group brD10 than in Group D10 on Day 5 post partum, 1 day after the end of bromocriptine treatment $(t=2 \cdot 84$, $P<0.05$ ). This shows that treatment with bromocriptine reduced the circulating concentration of prolactin.
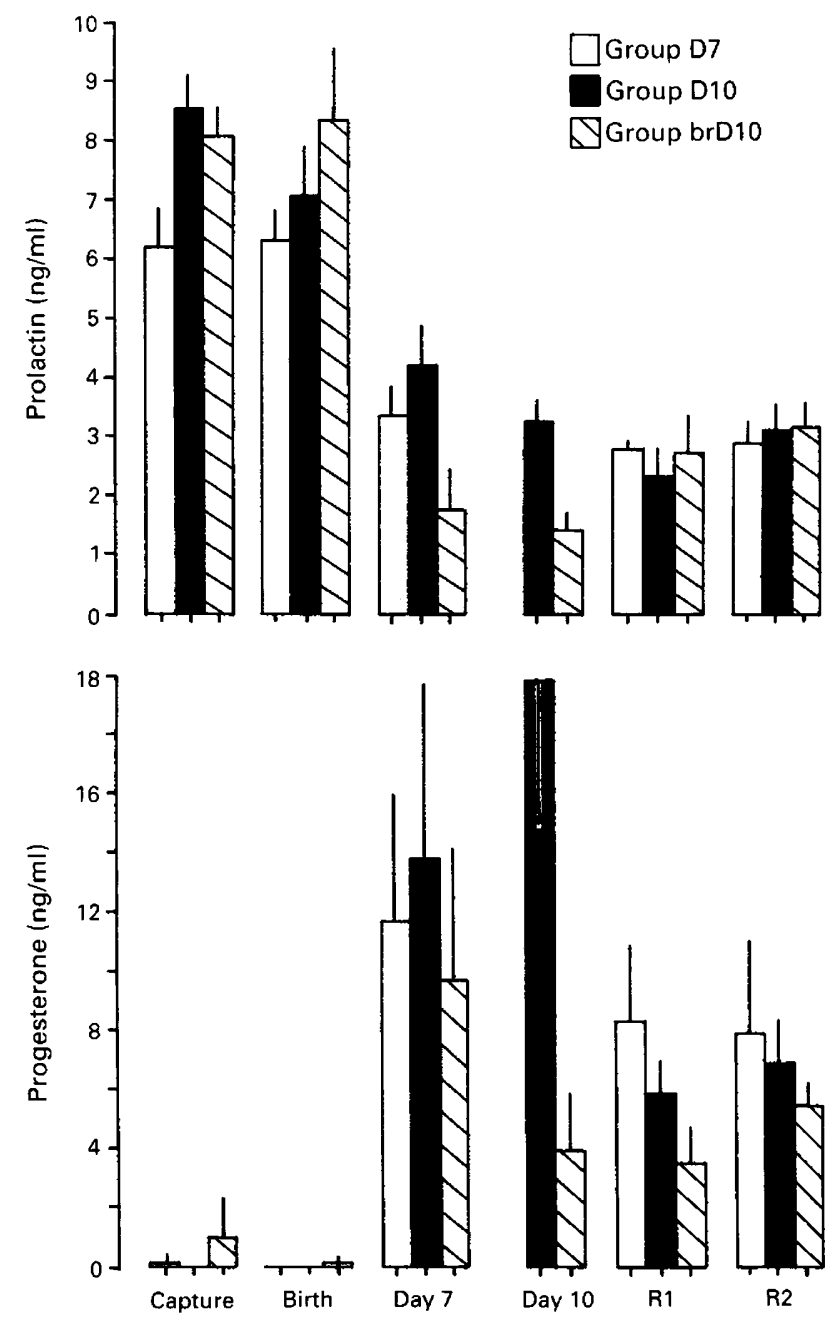

Fig. 3. Plasma prolactin (a) and progesterone (b) in seals of Groups D7, D10 and brD10 ( $\mathrm{N}=6$ in each group) at capture before birth, on the day of birth, on Days 7 and 10 after birth, on return to the breeding grounds after the first feeding trip (R1) and when released 2 days later (R2). 
On return from their first feeding trip to sea there was no significant difference in the plasma prolactin concentration between any of the groups $(P>0.1$ in all comparisons). There was similarly no difference between groups on the day when mothers were finally released $(P>0.01$ in all comparisons) (Fig. 3). All the groups showed a decline in plasma prolactin concentration from the time of capture until the time of final release, although the greatest change occurred between birth and Day 7 post partum. In Group brD10 seals there was a greater decline in plasma prolactin between parturition and Day 7 than in the other two groups.

The concentration of plasma progesterone was below $1 \mathrm{ng} / \mathrm{ml}$ in the three groups at capture and parturition (Fig. 3) which confirms the observations in Exps 1 and 2 of low progesterone concentrations at these stages. By Day 7 post partum, the plasma progesterone concentration in all groups had increased significantly $(P<0.01$ in all comparisons using paired $t$ tests), indicating that ovulation had occurred, and there was no significant difference between groups $(P>0 \cdot 1)$. However, by Day 10 post partum there was a significant difference between the plasma progestero:e concentrations in Groups D10 and brD10 $(t=3 \cdot 118, P<0.01)$. Plasma concentrations of prolactin increased to $20 \mathrm{ng} / \mathrm{ml}$ in Group D10 by Day 10 but were below $4 \mathrm{ng} / \mathrm{ml}$ in Group brD10 at the same time. However, by the time these seals returned from their first feeding trips to sea, the plasma concentration in Group D10 had declined to $6 \mathrm{ng} / \mathrm{ml}$ and was not significantly different from that in the other groups ( $P>0.01$ in each comparison) (Fig. 3).

Maternal mass was not significantly different between groups at capture or at parturition ( $P>0 \cdot 1$ in all comparisons) but mass declined during the period of captivity (Fig. 4). This was largely because females gave birth during the experiment but also because, in common with freeranging females at this stage of their cycle, they were fasting. The rate of mass loss after birth was greatest in Groups D7 and D10 and both were significantly greater than the rate in group brD10 up to Day 7 post partum (Table 1$)(t=2.654$ and 2.452 respectively, $P<0.05$ ). Between Days 7 and 10 post partum the rate of mass loss declined in Group D10 to a value which was significantly less than that of Group brD10 (Table 1). The implication of these observations is that mothers in Groups D7 and D10 experienced additional mass loss because they were lactating during the first 7 days post partum while mothers in Group brD10 failed to lactate.
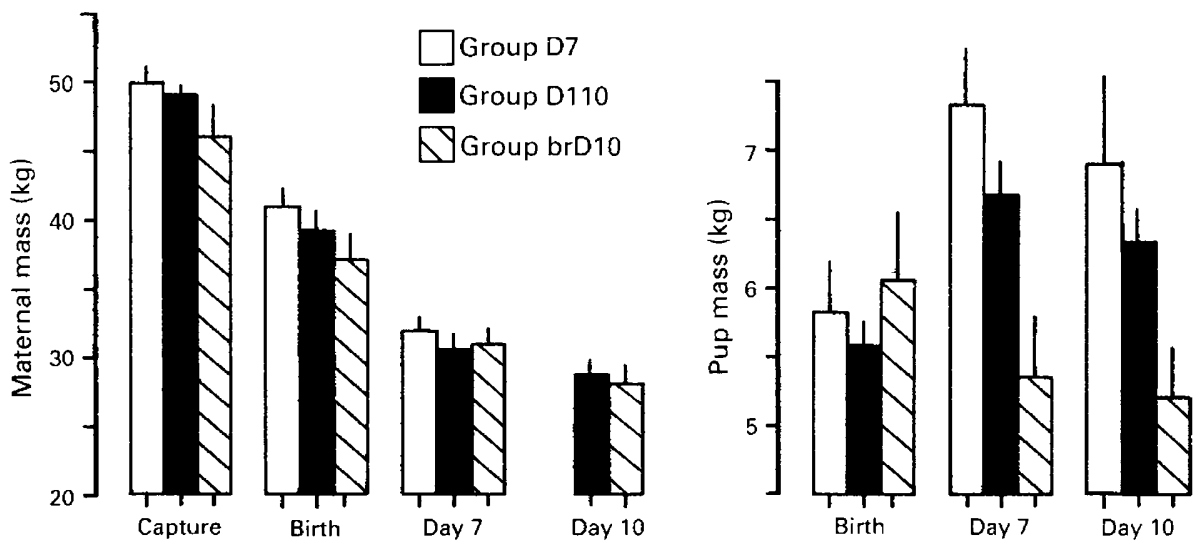

Fig. 4. Mass changes in female Antarctic fur seals (a) and their pups (b) in Groups D7, D10 and brD10 ( $\mathrm{N}=6$ in each group) at capture before birth, on the day of birth and on Days 7 and 10 after birth. Values are mean \pm s.e.m.

This is further illustrated by the mass changes in the pups of females from each group (Fig. 4). There was no significant difference between the birth mass of pups born to mothers from each group $(P>0 \cdot 1)$ but, by Day 7 , pups of mothers in Group brD10 had a significantly lower mass 
Table 1. The mean ( \pm s.e.) rates of mass gain by pups ( $\mathrm{kg} /$ day) and mass loss by mothers $(\mathrm{kg} /$ day) during the first 7 days after parturition and between 7 and 10 days after parturition in the different groups from Exp. 1

\begin{tabular}{llrc}
\hline & & \multicolumn{2}{c}{ Days after parturition } \\
\cline { 3 - 4 } Group & Mother/pup & \multicolumn{1}{c}{$0-7$} & \multicolumn{1}{c}{$7-10$} \\
\hline D7 & Mother & $-1 \cdot 262 \pm 0.085$ & - \\
& Pup & $0.217 \pm 0.028$ & $-0.229 \pm 0.143$ \\
D10 & Mother & $-1.226 \pm 0.082$ & $-0.639 \pm 0.117$ \\
& Pup & $0.157 \pm 0.016$ & $-0.111 \pm 0.059$ \\
brD10 & Mother & $-0.857 \pm 0.126$ & $-0.986 \pm 0.059$ \\
& Pup & $-0.102 \pm 0.021$ & $-0.153 \pm 0.021$ \\
\hline
\end{tabular}

than pups from the other groups $(P<0.02)$ and this difference was maintained until Day 10 (Fig. 4). Pups in Group D10 lost mass between Days 7 and 10 despite the presence of their mothers.

All seals departed for sea immediately they were released from the enclosure for the first time except 3 of the 6 seals in Group D7 which were mated before they departed to sea. No seals in the other two groups were mated after release.

\section{Discussion}

There is a remarkable degree of consistency of reproductive pattern across all pinniped species (Daniel, 1981; Boyd, 1990). The annual cycle of reproduction in the Antarctic fur seal is similar to, but 6 months out of phase with, that of its close relation, the northern fur seal (Callorhinus ursinus) (Craig, 1964). Daniel (1981) showed that the plasma progesterone concentrations of female northern fur seals, sampled in much the same way as in this study, remained at a low level until 1-4 weeks before implantation when there was a rapid increase. However, he was unable to obtain samples from females during post-implantation gestation and did not describe any detail of hormonal changes occurring during the perinatal period when oestrus and mating occur.

The increased concentration of progesterone in the samples obtained in March (Fig. 1) probably signals activation of the corpus luteum after a period of relative, although not complete, quiescence during embryonic diapause. There are no data from Antarctic fur seals to show when placentation occurs but regressing fetal length against date for large samples of northern fur seal fetuses has shown that implantation occurs 3-4 months after mating (Temte, 1985; Trites, 1990). Given that the same pattern of fetal growth is likely to occur in the Antarctic fur seal then, in this species, implantation will occur in mid-March.

The physiological importance of the activation of the corpus luteum is uncertain. Plasma progesterone increases towards the end of embryonic diapause in black bears (Ursus americanus) (Foresman \& Daniel, 1983) and amongst the mustelids which have delayed implantation, the corpus luteum is generally inactive throughout the period of diapause but shows reactivation before implantation (Mead, 1981). Ovariectomy in some species has demonstrated that the ovary is necessary for long-term blastocyst survival (Mead, 1981). It is uncertain whether the low concentration of progesterone in the circulation during diapause, as observed in this study, originates from the corpus luteum. In unmated hooded seals (Cystophora cristata), plasma progesterone concentrations appear to remain slightly elevated for approximately the same duration as the period of embryonic diapause and then decline (Noonan \& Ronald, 1989). This was predicted by Boyd (1984) and Reijnders (1990) has made a similar observation for harbour seals (Phoca vitulina) which suggests that the elevated plasma progesterone concentrations during embryonic diapause are independent of the presence of a blastocyst. Thus, after ovulation seals may enter a period 
of pseudopregnancy the duration of which is roughly equivalent to the duration of embryonic diapause.

Daniel (1981) failed to reactivate the blastocysts of northern fur seals prematurely by treatment with exogenous progesterone or oestradiol-17 $\beta$. This suggests that changes in these steroids at or before the time of implantation are possibly a consequence and not the cause of blastocyst implantation. In mink (Mustela vison), another species which shows delayed implantation (Sundqvist et al., 1989), implantation is also marked by an increase in plasma progesterone but this is preceded by increasing plasma prolactin (Martinet et al., 1981). Treatment of mink with exogenous prolactin can advance the time of implantation (Papke et al., 1980; Murphy et al., 1981; Martinet et al., 1981). The pattern of prolactin secretion during the annual cycle in Antarctic fur seals suggests a role for prolactin different from that in mink because there was a gradual decline in plasma concentrations throughout embryonic diapause.

Temte (1985) recognized the significance of the timing of implantation in fur seals in relation to the annual cycle of photoperiod. The extreme synchrony of births, both within and between years (Duck, 1990), suggests that the timing of reproduction is linked to a highly predictable environmental variable like photoperiod. In species which are distributed over a wide range of latitude, such as the northern and Antarctic fur seals, individuals will be exposed to different photoperiodic conditions except during the equinoxes. Synchrony within the whole population may, therefore, only be achieved by using the equinoctial photoperiod to stimulate blastocyst reactivation. Evidence from this study suggests that reactivation in the Antarctic fur seal does occur close to the autumnal equinox.

While the plasma hormone profiles during the post partum oestrous cycle showed some variation between individuals, there was a consistent general pattern. This involved elevation of prolactin soon after parturition followed closely by elevation of oestradiol, probably associated with the development of the preovulatory follicle. There then followed a decline of these hormones before a second increase in oestradiol, which occurred in some cases simultaneously with the rapid rise in progesterone at ovulation and was probably of luteal or interstitial origin. In grey seals (Halichoerus grypus) and southern elephant seals (Mirounga leonina) a wave of follicle development follows parturition (Laws, 1956; Boyd, 1983) and this leads to a single preovulatory follicle being present in one ovary by the time of oestrus. Folliculogenesis is similar in the northern fur seal (Craig, 1964) and the pattern of hormone secretion in the post-partum period suggests that the same sequence of events occurs in the Antarctic fur seal.

Prolactin has been recognized as an important hormone in the development of the corpus luteum of several carnivores (Murphy, 1979; Murphy et al., 1981; Agu et al., 1986; Concannon et al., 1987). Measurements of seal peptide hormones are limited by the lack of fully varifiable hormone assays and in this study prolactin concentration can only be considered in relative rather than absolute terms because measurements were made using an assay for human prolactin. However, this study has shown that reduction of prolactin by bromocriptine treatment during the preovulatory period caused the failure of the peri-ovulatory peak of progesterone (Fig. 3). The long-term consequences of this for reproduction were not addressed in this study but, in sheep (Ovis $\mathrm{sp}$.), prolonged suppression of prolactin during oestrous cycles can reduce the ovulation rate (Rodway et al., 1983). Therefore, ovulation may have been suppressed in seals treated with bromocriptine although further experiments are required to test this.

This study has also demonstrated that Antarctic fur seals ovulate in the absence of being mated, as judged by the presence of a corpus luteum in the ovaries after the normal period of oestrus, and that the post-ovulatory concentrations of progesterone and prolactin are similar in seals whether or not they have been mated. Several seals in Group D7 of Exp. 3 were mated when released from the enclosure but no relationship was found between subsequent plasma hormone concentrations and the occurrence of mating. Several studies have demonstrated the presence of apparently active corpora lutea in pinniped ovaries after mating (Craig, 1964; Sinha \& Erickson, 1972; Bigg \& Fisher, 1975; Boyd, 1984; Hill, 1987) and comparisons with mustelids would suggest that seals are induced 
ovulators. However, this study has demonstrated that spontaneous ovulation occurs in the Antarctic fur seal. Northern fur seal females prevented from being mated at the post-partum oestrus do not give birth in the following season (Gentry, 1981), showing that the northern fur seal is monoestrous; it seems probable that Antarctic fur seals are also monoestrous.

Reactivation of the blastocyst, defined by increasing plasma progesterone, occurred before weaning suggesting that there is no direct link between weaning and blastocyst reactivation. In most fur seals, lactation lasts at least 1 year (Oftedal et al., 1987; Boyd, 1990) and during this time females are normally pregnant. The northern and Antarctic fur seals are thought to have shorter periods of lactation because of the special circumstances associated with the feeding ecology of these seals in the seasonal environments at high latitudes (Gentry et al., 1986). Therefore, from the pattern seen in other closely related species a close link between the physiological changes associated with the termination of diapause and with weaning would not have been predicted.

Prolactin concentrations are elevated before parturition and this suggests that prolactin has a role in the development of mammary function. Reduction of prolactin secretion by treatment with bromocriptine during the perinatal period caused termination of lactation, as judged by the reduced rate of mass loss by mothers and the decline of pup mass when the mass of pups in the control groups increased. Therefore, prolactin secretion, at least in the early stages of lactation, appears to be vital for the maintenance of lactation. It would also appear that prolactin secretion in Antarctic fur seals is under dopaminergic control because bromocriptine is a known dopamine agonist (e.g. Agu et al., 1986).

Lactation in Antarctic fur seals is unusual for mammals because lactating mothers normally leave their pups for several days during feeding trips at sea (Doidge \& Croxall, 1989). This suggests that positive feedback from nipple stimulation during suckling is unlikely to be as important for the maintenance of lactation in fur seals as it is in some other mammals (e.g. McNeilly et al., 1982; Loudon et al., 1983; Schirar et al., 1990). In this study, mothers kept in the enclosure for up to 10 days post partum stopped lactating after Day 7 when females would normally have gone to sea, as judged by the decline in pup mass over this period. While prolactin concentrations were relatively low at this time there was no evidence of a sharp decline associated with the temporary termination of lactation and prolactin had not increased significantly when females returned to feed their pups after their first feeding trip. Therefore, although lactation can be terminated by the artificial reduction of prolactin, the lactation cycles in Antarctic fur seals, which involve mothers going to sea to feed, are unlikely to be caused by a similar endogenous process.

I thank T. Barton, N. J. Lunn, S. Rodwell and T. D. Williams for assistance in the field.

\section{References}

Agu, G.O., Rajkumar, K. \& Murphy, B.D. (1986) Evidence for dopaminergic regulation of prolactin and a luteotrophic complex in the ferret. Biol. Reprod. 35, 508-515.

Bigg, M.A. \& Fisher, H.D. (1975) Effect of photoperiod on annual reproduction in female harbour seals. Rapp. P.-V. Reun. Cons. Int. Explor. Mer. 169, 141-144.

Boyd, I.L. (1983) Luteal regression, follicle growth and the concentration of some plasma steroids during lactation in grey seals (Halichoerus grypus). J. Reprod. Fert. 69, 157-164.

Boyd, I.L. (1984) Development and regression of the corpus luteum in grey seal (Halichoerus grypus) ovaries and its use in determining fertility rates. Can. J. Zool. 62, 1095-1100.

Boyd, I.L. (1989) Spatial and temporal distribution of Antarctic fur seals (Arctocephalus gazella) on the breeding grounds at Bird Island, South Georgia, Polar Biol. 10, 179-185.

Boyd, I.L. (1990) Environmental and physiological factors controlling the reproductive cycles of pinnipeds. Can. J. Zool. in press.

Boyd, I.L. \& McCann, T.S. (1989) Pre-natal investment in reproduction by female Antarctic fur seals. Behav. Ecol. Sociobiol. 24, 377-385.

Concannon, P.W., Weinstein, P., Whaley, S. \& Frank, D. (1987) Suppression of luteal function in dogs by luteinizing hormone antiserum and by bromocriptine. J. Reprod. Fert. 81, 175-180.

Costa, D.P., Croxall, J.P. \& Duck, C. (1989) Foraging energetics of Antarctic fur seals in relation to changes in prey availability. Ecology 70, 596-606.

Craig, A.M. (1964) Histology of reproduction and the estrus cycle in the female fur seal, Callorhinus ursinus. J. Fish. Res. Bd Can. 21, 773-811. 
Croxall, J.P., McCann, T.S., Prince, P.A. \& Rothery, P. (1988) Reproductive performance of seabirds and seals at South Georgia and Signy Island, South Orkney Islands, 1976-1987: implications for Southern Ocean monitoring studies. In Antarctic Ocean and Resource Variability, pp. 261-285. Ed. D. Sahrhage. Springer-Verlag, Berlin.

Daniel, J.C. (1981) Delayed implantation in the northern fur seal (Callorhinus ursinus) and other pinnipeds. $J$. Reprod. Fert., Suppl. 29, 35-50.

Doidge, D.W. \& Croxall, J.P. (1989) Factors affecting weaning weight in Antarctic fur seals Arctocephalus gazella at South Georgia. Polar Biol. 9, 155-160.

Doidge, D.W., McCann, T.S. \& Croxall, J.P. (1986) Attendance behaviour of Antarctic fur seals. In Fur seals, Maternal Strategies on Land and at Sea, pp. 102-114. Eds R. L. Gentry \& G. L. Kooyman. Princeton University Press, Princeton.

Duck, C.D. (1990) Annual variation in the timing of reproduction in Antarctic fur seals, Arctocephalus gazella, at Bird Island, South Georgia. J. Zool., Lond.

Foresman, K.R. \& Daniel, J.C. (1983) Plasma progesterone concentrations in pregnant and non-pregnant black bears (Ursus americanus). J. Reprod. Fert. 68, 235-239.

Gentry, R.L. (1981) Northern fur seal-Callorhinus ursinus. In Handbook of Marine Mammals, pp. 143160. Eds S. H. Ridgeway \& R. J. Harrison. Academic Press, London.

Gentry, R.L. \& Holt, J.R. (1982) Equipment and techniques for handling northern fur seals. US. Dept. Commerce. NOAA Tech. Rep., NMFS SSRF-758, $15 \mathrm{pp}$.

Gentry, R.L., Costa, D.P., Croxall, J.P., David, J.H.M., Davis, R.W., Kooyman, G.L., Majluf, P., McCann, T.S. \& Trillmich, F. (1986) Synthesis and conclusions. In Fur Seals-Maternal Strategies on Land and at Sea, pp. 220-282. Eds R. L. Gentry \& G. L. Kooyman. Princeton University Press, Princeton.

Hill, S.E.B. (1987) Reproductive ecology of Weddell seals (Leptonychotes weddelli) in McMurdo Sound, Antarctica. Ph.D. thesis, University of Minnesota, 106 pp.

Laws, R.M. (1956) The elephant seal (Mirounga leonina Linn.). III. The physiology of reproduction. Scient. Rep. Falk. Isl. Depend. Surv. 115, 1-66.

Loudon, A.S.I., McNeilly, A.S. \& Milne, J.A. (1983) Nutrition, milk yield and suckling behaviour in red deer: implications for lactational control of fertility. Nature, Lond. 302, 145-147.

Martinet, L., Allais, C. \& Allain, D. (1981) The role of prolactin and $\mathrm{LH}$ in luteal function and blastocyst growth in mink (Mustela vison). J. Reprod. Fert., Suppl. 29, 119-130.
McNeilly, A.S., Glasier, A., Jonassen, J. \& Howie, P.W. (1982) Evidence for direct inhibition of ovarian function by prolactin. J. Reprod. Fert. 65, 559-569.

Mead, R.A. (1981) Delayed implantation in mustelids, with special emphasis on the spotted skunk. $J$. Reprod. Fert. 29, 11-24.

Murphy, B.D. (1979) The role of prolactin in implantation and luteal maintenance in the ferret. Biol. Reprod. 21, 517-521.

Murphy, B.D., Concannon, P.W., Travis, H.F. \& Hansel, W. (1981) Prolactin: the hypophyseal factor that terminates embryonic diapause in mink. Biol. Reprod. 25, 487-491.

Noonan, L.M. \& Ronald, K. (1989) Determination of estrone sulfate, progesterone and testosterone for hooded seals, Cystophora cristata. 8th Biennial Conference on the Biology of Marine Mammals, Pacific Grove, California, 1989. Abstract p. 46.

Oftedal, O.T., Boness, D.J. \& Tedman, R.A. (1987) The behaviour, physiology and anatomy of lactation in the Pinnipedia. Curr. Mammal. 1, 175-245.

Papke, R., Concannon, P.W., Travis, H. \& Hansel, W. (1980) Control of luteal function and implantation in the mink by prolactin. J. Anim. Sci. 50, 1102-1107.

Raeside, J.I. \& Ronald, K. (1981) Plasma concentrations of oestrone, progesterone and corticosteroids during late pregnancy and after parturition in the harbour seal, Phoca vitulina. J. Reprod. Fert. 61, 135-139.

Reijnders, P.J.H. (1990) Progesterone and oestradiol$17 \beta$ concentration profiles throughout the reproductive cycles in harbour seals (Phoca vitulina). $J$. Reprod. Fert. 90, 403-409.

Rodway, R.G., Robinson, J.J. \& Phillippo, M. (1983) Ovulation in induced oestrous cycles of anoestrous ewes given bromocriptine. J. Reprod. Fert. 68, 265-267.

Schirar, A., Cognie, Y., Louault, F., Poulin, N., Meusnier, C., Levasseur, M.C. \& Martinet, J. (1990) Resumption of gonadotrophin release during the post-partum period in suckling and non-suckling ewes. $J$. Reprod. Fert. 88, 593-604.

Sinha, A.A. \& Erickson, A.W. (1972) Ultrastructure of the corpus luteum of implantation and pregnancy in Carnivora. In Electron Microscope Concepts of Secretion, pp. 53-69. Ed. M. Hess. Wiley, New York.

Sundqvist, C., Amador, A.G. \& Bartke, A. (1989) Reproduction and fertility in the mink (Mustela vison). $J$. Reprod. Fert. 73, 127-131.

Temte, J.L. (1985) Photoperiod and delayed implantation in the northern fur seal (Callorhinus ursinus). $J$. Reprod. Fert. 73, 127-131.

Trites, A.W. (1990) Fetal growth of northern fur seals Callorhinus ursinus. Can. J. Zool. in press.

Received 13 July 1990 